Silva, VP \& Souza, SKS. (2020). Environmental characterization of a filling station from the standpoint of environmental adaptation. Research, Society and Development, 9(7): 1-24, e368973527.

\title{
Caracterização ambiental de posto de revenda de combustíveis sob a ótica de adequação ambiental
}

Environmental characterization of a filling station from the standpoint of environmental adaptation

\section{Caracterización ambiental de una estación de reventa de combustible desde la perspectiva de adecuación ambiental}

Recebido: 06/04/2020 | Revisado: 17/04/2020 | Aceito: 04/05/2020 | Publicado: 17/05/2020

\section{Valdenildo Pedro da Silva}

ORCID: https://orcid.org/0000-0002-9897-0026

Instituto Federal do Rio Grande do Norte, Brasil

E-mail: valdenildo.silva@ifrn.edu.br

Sharlene Karla dos Santos Souza

ORCID: https://orcid.org/0000-0001-6908-9419

Instituto de Desenvolvimento Sustentável e Meio Ambiente do RN, Brasil

E-mail: sharlenekarla@gmail.com

\section{Resumo}

O propósito deste estudo é caracterizar a situação ambiental de um posto de revenda de combustíveis da cidade de Mossoró, no estado do Rio Grande do Norte, sob o prisma da adequação ambiental às condições do meio onde se insere, assim como aos regulamentos ambientais pertinentes. A partir disso, um estudo de caso exploratório-descritivo foi aplicado a um dos postos de revenda de combustíveis da cidade, no qual a problemática se evidenciou mais proeminente. Os resultados do estudo revelaram que o local de revenda de combustíveis inovou e, dentre alguns aspectos de adequação ambiental, mereceu destaque a instalação de câmara de contenção nos respiros dos tanques de armazenamento de combustíveis, com vistas a evitar vazamentos. Entretanto, o ambiente caracterizou-se como parcialmente inadequado às condições do meio local e aos regulamentos ambientais, devido ao fato de apresentar ineficiência na caixa separadora de água e óleo, danos nas câmaras de contenção de bombas e filtros e destinação final inadequada dos resíduos classe I, considerados como perigosos por serem causadores de riscos ao meio ambiente e à saúde pública, principalmente de moradores 
circunvizinhos. Constatou-se, ainda, a inexistência de monitoramento ambiental contínuo, por parte do órgão responsável pelo licenciamento ambiental. Recomenda-se, portanto, intervenções em direção à sustentabilidade ao posto de revenda de combustíveis e ao órgão ambiental licenciador.

Palavras-chave: Adequação ambiental; Posto de combustível; Direito ambiental; Legislação ambiental; Licenciamento ambiental.

\begin{abstract}
As such, the aim of this study was to characterize the environmental situation of a filling station in Mossoró, Rio Grande do Norte state, Brazil, from the standpoint of adapting to current environmental regulations. Next, an exploratory-descriptive case study was carried out at one of the filling stations of the city, where the problem was more serious. The results revealed that the station installed an overfill protection containment chamber in the fuel storage tanks, in order to avoid leaks. However, the environment was partially inadequate due to the inefficiency of the oil-water separator system, damage to contention chamber pumps and filters and unsuitable final destination for class 1 waste, considered dangerous to the environment and public health, especially nearby inhabitants. In addition, there is no continuous monitoring by the environmental licensing department. It is therefore recommended that interventions aimed at sustainability of the filling station be implemented by the licensing entity.
\end{abstract}

Keywords: Environmental adaptation; Filling station; Environmental law; Environmental legislation; Environmental licensing.

\title{
Resumen
}

El propósito de este estudio es caracterizar la situación ambiental de un puesto de reventa de combustible en la ciudad de Mossoró, en el estado de Rio Grande do Norte, bajo el prisma de adecuación ambiental a las condiciones del entorno en el que opera, así como a las regulaciones ambientales relevantes. En base a esto, se aplicó un estudio de caso descriptivo exploratorio a una de las estaciones de reventa de combustible de la ciudad, en el que el problema se hizo más prominente. Los resultados del estudio revelaron que el sitio de reventa de combustible fue innovador y, entre algunos aspectos de la adecuación ambiental, la instalación de una cámara de contención en los respiraderos de los tanques de almacenamiento de combustible merecía mención, para evitar fugas. Sin embargo, el medio ambiente se caracterizó como parcialmente inadecuado para las condiciones del medio 
ambiente local y las regulaciones ambientales, debido al hecho de que presenta ineficiencia en la caja separadora de agua y aceite, daños en las cámaras de contención de bombas y filtros y destino final inadecuado de los desechos de la clase. I, considerado como peligroso porque causan riesgos para el medio ambiente y la salud pública, principalmente de los residentes de los alrededores. También hubo una falta de monitoreo ambiental continuo por parte de la agencia responsable de la licencia ambiental. Por lo tanto, se recomiendan intervenciones hacia la sostenibilidad para el puesto de reventa de combustible y la agencia de licencias ambientales.

Palabras clave: Adecuación ambiental; Gasolinera; Derecho ambiental; Legislación ambiental. Licencias ambientales.

\section{Introdução}

Neste limiar de século, diante das crises civilizatórias multidimensionais eclodidas, passou-se a compreender o desenvolvimento sustentável, ou melhor, a sustentabilidade como um princípio central às estratégias de gestão de organizações. Postos de revenda de combustíveis (PRC), dispersos pelo Brasil, têm empregado estratégias sustentáveis, centradas prioritariamente em dimensões socioeconômicas. Tais organizações são autorizadas a funcionar no território brasileiro pela “Agência Nacional do Petróleo, Gás Natural e Biocombustíveis" (ANP), para que atuem na revenda varejista de combustíveis automotivos e prestação de serviços (ANP, 2019). Elas contribuem para o desenvolvimento sustentável, ou sustentabilidade, do país, pois são geradoras de emprego, ocupações e de renda, além de serem fornecedoras de energia que dinamiza a economia e o desenvolvimento social.

Contudo, apesar disso, poucos estudos empíricos têm procurado dar ênfase aos desafios de adequação ambiental desses tipos de organizações frente ao potencial poluidor e degradador, principalmente de solos, águas e pessoas. Ou seja, essas organizações são difusoras, também, de desafios ao desenvolvimento sustentável ou a sustentabilidade, uma vez que constituem potenciais geradores de vazamentos de derivados de petróleo, de resíduos, causando impactos negativos ao solo e às águas subterrâneas, gerando passivos ambientais. Dessa forma, os PRCs podem afetar a saúde e o bem-estar de pessoas e de comunidades se não estiverem, em algum aspecto, adequados ambientalmente (Amaral et al., 2017; Costa \& Goldbaum, 2017; Guerra \& Fontes, 2017; Maksoud et al., 2019; Skamvetsakis et al., 2017; Sousa \& Cardoso, 2017; Zucki et al., 2017).

Entende-se adequação ambiental como sendo o desenvolvimento de uma atividade 
socioeconômica em total harmonia ou em conformidade com as condições do ambiente, no qual o empreendimento possa vir a ser ou esteja implantado, considerando-se aspectos físico, químico, biológico e humano, recorrendo-se, também, aos regulamentos ambientais, sob o risco de acarretar algum dano ambiental (Milaré, 2015; Souza \& Silva, 2018; Trennepohl \& Trennepohl, 2016).

Nessa perspectiva, a adequação ambiental de um PRC consiste no desenvolvimento de suas atividades em consonância com os ritmos ou condições da natureza. Para que isso ocorra, é necessário que sejam consideradas as condições do ambiente natural, bem como normas ambientais brasileiras pertinentes, pois elas estabelecem parâmetros para proteção contra vazamentos, derramamentos, transbordamento, poluição atmosférica, redução de riscos, aquisição da licença ambiental, treinamento de pessoal e destinação final adequada dos resíduos perigosos na direção da sustentabilidade (Associação Brasileira de Normas Técnicas, 1994; 2004; 2006; 2010; 2013; 2014; 2019; Dias, 2012; Souza \& Silva, 2018)

Com o intuito de defender e de preservar o meio ambiente, a resolução CONAMA $\mathrm{n}^{\circ}$ 237, de 19 de dezembro de 1997, regimentou questões do licenciamento ambiental estabelecidas anteriormente na lei 6.938 de 1981, contemplando tipos e prazos de licenças ambientais, além das competências entre União, Estados, Distrito Federal e Municípios para licenciar os diversos tipos de empreendimentos. Além do mais, na resolução CONAMA 273/2000, encontram-se as diretrizes específicas vigentes para o licenciamento ambiental de PRCs (Brasil, 1997; Brasil, 2000; Milaré, 2015).

Objetivando controlar e prevenir a poluição gerada pela atividade de revenda de combustíveis, tal resolução abarca os documentos básicos necessários para o licenciamento ambiental dos PRCs, inclusive por tipo de licença (Licença Prévia, Licença de Instalação e Licença de Operação). Ela estabelece, ainda, que o órgão ambiental competente, seja ele federal, estadual ou municipal, é responsável, também, pela fiscalização dos PRCs, não apenas pelo licenciamento ambiental (Brasil, 2000).

Nessa perspectiva, têm-se, ainda, as normas brasileiras protetivas elaboradas pela Associação Brasileira de Normas Técnicas (ABNT), as quais especificam projetos, equipamentos, medidas de segurança e procedimentos a serem adotados nos PRCs. Tais normas abordam algumas categorias importantes como: proteção contra vazamentos, derramamentos, transbordamento, poluição atmosférica, redução de riscos, aquisição da licença ambiental, treinamento de pessoal e destinação final dos resíduos perigosos (ABNT, 1994; 2004; 2006; 2010; 2013; 2014; 2019).

No âmbito estadual, no que diz respeito à proteção ambiental, o Rio Grande do Norte 
$(\mathrm{RN})$ possui a Lei Complementar $\mathrm{n}^{\mathrm{o}}$ 272. Essa lei institui a Política Estadual de Meio Ambiente com o foco de implantar requisitos imprescindíveis ao desenvolvimento sustentável do estado. Isso ocorre por meio dos princípios do uso responsável dos recursos ambientais, bem como por intermédio do acesso equitativo, da precaução, da prevenção e da proteção desses recursos, além da informação ambiental do usuário e poluidor-pagador, e da reparação ambiental. Essa lei complementar, bem como a resolução CONAMA n ${ }^{\circ} 237$, contemplam o licenciamento ambiental de empreendimentos e de atividades que, em nível estadual, possuem outros tipos de licenças. Além das Licenças Prévia (LP), de Instalação (LI) e, de Operação (LO) da resolução nacional, o RN possui, ainda, Licença Simplificada (LS), Licença de Instalação e Operação (LSIO), Licença de Alteração (LA) e Licença de Regularização de Operação (LRO). O enquadramento dos empreendimentos nessas licenças depende do seu porte e potencial poluidor (Rio Grande do Norte, 2004).

O Estado do Rio Grande do Norte, além dessa lei complementar, possui uma resolução específica sobre licenciamento ambiental de PRCs, que abrange também outras atividades geradoras de resíduos oleosos, como troca de óleo e lavagem de veículos. A resolução CONEMA nº 06 traz, em seu escopo, diretrizes para a instalação, operação, destinação de resíduos perigosos, elaboração do Estudo de Investigação de Passivo Ambiental (a fim de verificar se há contaminação na área do empreendimento) e do Estudo de Investigação Detalhada da qualidade do solo e água subterrânea e avaliação de risco (Rio Grande do Norte, 2011). Atualmente, existem no Estado 605 PRC, dos quais 56 se encontram no município de Mossoró, tornando-o, numericamente, o segundo maior do estado (ANP, 2019), onde as inadequações socioambientais são mais perceptíveis e pouco estudadas.

Diante dos impactos ambientais e ocupacionais, decorrentes do armazenamento e comercialização de combustíveis, em 2013 ocorreu a implantação do Projeto de Adequação Ambiental de Postos de Combustíveis no município de Mossoró-RN, mais conhecido como Selo Verde. A iniciativa do Ministério Público do estado do Rio Grande do Norte (MP-RN), era a de averiguar a adequação ambiental dos PRCs, visando a sustentabilidade social dessa atividade econômica (Dias, 2012; Guerra \& Fontes, 2017). Os peritos do MP-RN utilizaramse de um checklist, desenvolvido por eles e baseado nas normas ambientais vigentes, para atestar a adequação ambiental dos PRCs de Mossoró-RN (Souza \& Silva, 2018).

Todavia, constatou-se que dos 56 PRCs existentes em Mossoró (ANP, 2019), 05 deles não aderiram ao Projeto de Adequação Ambiental. Para alguns dos proprietários desses estabelecimentos, a adesão ao projeto significava apenas aumento de custos. Para outros, essa adesão era desnecessária, já que seus PRCs haviam sido construídos recentemente com 
equipamentos ecológicos e dispõem de licença ambiental. Entretanto, ter posse de uma licença ambiental não significa que o empreendimento atende a todas as normas ambientais de proteção contra vazamentos, derramamentos, transbordamento, poluição atmosférica, redução de riscos, treinamento de pessoal e destinação final dos resíduos perigosos (ABNT, 1994; 2004; 2006; 2010; 2013; 2014; 2019). Isso significa que, mesmo com a licença, o cumprimento das condicionantes citadas no termo tende a ser negligenciado pelos empreendedores (Trennepohl \& Trennepohl, 2016), sendo averiguado, normalmente, pelo órgão ambiental apenas na renovação da concessão.

Além de inadequações ambientais percebidas a priori, contatou-se, também, em relação à revisão de literatura a inexistência de artigos de pesquisa ou de revisão sobre adequação ambiental de PRCs. Dos estudos levantados, o foco dos artigos de pesquisa era na saúde dos funcionários e da população como um todo, abordando a toxicidade das substâncias químicas do grupo BTEX e o seu potencial cancerígeno e carcinogênico, principalmente relacionados ao benzeno (Amaral et al., 2017; Costa \& Goldbaum, 2017; Maksoud et al., 2019; Skamvetsakis et al., 2017; Sousa \& Cardoso, 2017; Zucki et al., 2017). Além do impacto na saúde, os trabalhos encontrados abordavam basicamente sobre técnicas de remediação da contaminação e de plumas de contaminação por hidrocarbonetos derivados do petróleo (Corseuil et al., 2011; Freire at al., 2014; Heibati et al., 2018; Mariano et al., 2007; Souza \& Silva, 2018).

Considerando o exposto, indagou-se: qual é a situação ambiental de um posto de revenda de combustíveis da cidade de Mossoró-RN, não integrante do Projeto Selo Verde do Ministério Público do Rio Grande do Norte, quanto à sua adequação ambiental numa perspectiva sustentável?

Portanto, o objetivo deste estudo é caracterizar a situação ambiental de um posto de revenda de combustíveis da cidade de Mossoró, no Estado do Rio Grande do Norte, sob o prisma da adequação ambiental às condições do meio onde se insere, assim como aos regulamentos ambientais pertinentes.

\section{Metodologia}

Trata-se de um estudo de caráter qualitativo, descritivo, documental e de natureza exploratória como preconiza Pereira et al. (2018) e, para o qual se investigou o caso da situação ambiental de um PCR, nomeado de maneira fictícia de Posto Terra do Sal, para preservar o anonimato da razão social ou do nome de fantasia do empreendimento. Considera- 
(CC BY 4.0) | ISSN 2525-3409 | DOI: http://dx.doi.org/10.33448/rsd-v9i7.3527

se como um estudo de caso, devido ao fenômeno da inadequação ambiental ser mais proeminente no Posto Terra do Sal, com características ambientais ou particularidades diferentes dos demais postos de combustíveis existentes da cidade (Yin, 2015; Pereira et al., 2018).

A área objeto de interesse do estudo, o PCR escolhido, localiza-se na cidade de Mossoró-RN, situada na mesorregião e microrregião Oeste Potiguar do estado do Rio Grande do Norte, Brasil, distante cerca de $277 \mathrm{~km}$ da capital do Estado, conforme pode ser observado na Figura 1.

Figura 1 - Mapa de localização do Posto Terra do Sal na cidade de Mossoró-RN, Rio Grande do Norte, Brasil.
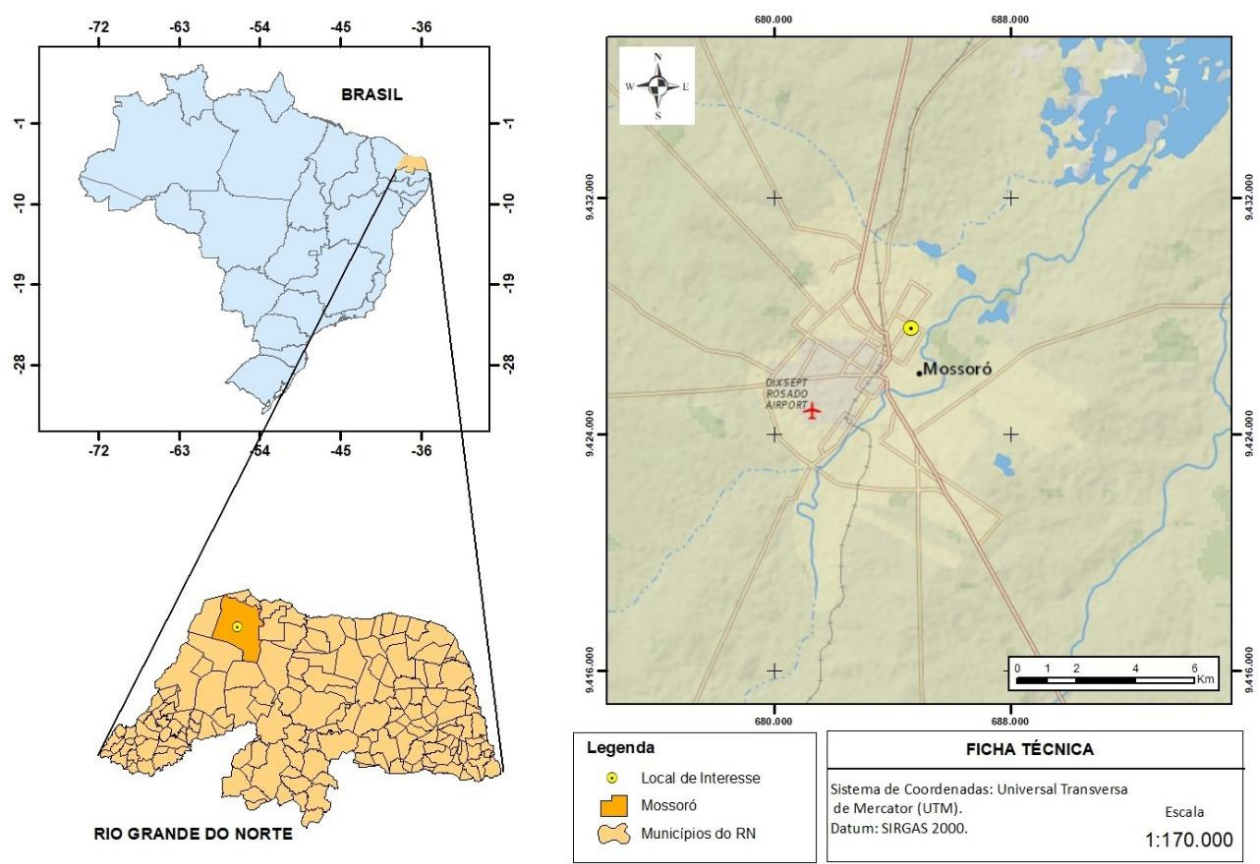

Fonte: Autores (2020).

Para a obtenção dos dados sobre o PCR, situado na cidade de Mossoró-RN, Rio Grande do Norte, Brasil, optou-se pela utilização método checklist, desenvolvido pelos peritos do MP-RN para o Projeto Selo Verde, por meio do qual foram coletadas informações pertinentes à análise crítica da adequação ambiental do Posto Terra do Sal. O checklist se destaca pela padronização na verificação dos resultados e, assim, tem sido usado como uma ferramenta hábil para a aquisição de dados (Barros, 2006; Kerber, 2013). Neste caso específico, o checklist possibilitou o levantamento de dados das seguintes etapas de adequação ambiental do PCR, como: proteção contra vazamentos; proteção contra derramamentos; proteção contra transbordamento; proteção contra poluição atmosférica; 
redução de riscos; licença ambiental válida; passivo ambiental; treinamento de pessoal e destino final dos resíduos perigosos (Dias, 2012; Souza \& Silva, 2018).

Para a consecução deste estudo, utilizou-se de levantamento dados secundários, primeiramente do órgão ambiental licenciador, o Instituto de Desenvolvimento Sustentável e Meio Ambiente do Rio Grande do Norte (IDEMA) e, na sequência, no Posto Terra do Sal. Por meio de observações diretas no PCR, buscou-se diagnosticar a situação ambiental utilizando registro fotográfico e preenchimento de um checklist (Dias, 2012). A análise documental foi fundamental para conhecimento da situação estrutural do posto, bem como da localização, da circunvizinhança, dos projetos, dentre outros aspectos. Além disso, foi realizada, para a conclusão da coleta de dados, vistorias in loco no Posto Terra do Sal, a fim de reiterar ou não as informações obtidas na análise documental, além de complementar as informações obtidas pela aplicação do checklist.

As investigações começaram a ocorrer a partir do mês de abril de 2019, sempre acompanhadas pelo proprietário da organização e por dois funcionários. Os dados, coletados pelo checklist foram analisados, considerando-se as seguintes categorias: proteção contra vazamentos, derramamentos, transbordamento, poluição atmosférica, redução de riscos, aquisição da licença ambiental, treinamento de pessoal e destinação final dos resíduos perigosos foram avaliadas à luz das normas ambientais vigentes e dos aportes teóricos adotados.

Nessa perspectiva, a identificação da situação ambiental de cada uma das categorias mencionadas anteriormente, foi baseada em alguns parâmetros qualitativos, denominados de variantes, derivados da legislação ambiental estadual e federal, bem como de normas técnicas da ABNT referentes a PRC e aportes legais. Assim, o Posto Terra do Sal teve cada uma das variantes analisadas e, em seguida, classificadas como conforme, não conforme e não se aplica, como apresentado nos resultados a seguir.

\section{Resultados e Discussão}

Os resultados do estudo demonstraram que o Posto Terra do Sal apresentou poucas não conformidades, referentes a equipamentos instalados e destinação de resíduos, quando comparado às condições do meio onde se insere e às normas ambientais. Essas não conformidades se concentraram nas variantes câmaras de contenção (bombas e filtros) e caixa separadora de água e óleo, além da categoria destinação de resíduos classe I (perigosos).

No tocante à categoria proteção contra vazamentos, constatou-se que o Posto Terra do 
(CC BY 4.0) | ISSN 2525-3409 | DOI: http://dx.doi.org/10.33448/rsd-v9i7.3527

Sal se apresentou "conforme" para os tanques de armazenamento subterrâneo de combustíveis, pois são ecológicos. Esse posto possui 03 tanques, sendo um pleno, com capacidade de armazenamento de $15 \mathrm{~m}^{3}$, e 02 tanques bipartidos, com capacidade de $30 \mathrm{~m}^{3}$ cada, totalizando $75 \mathrm{~m}^{3}$ de armazenamento subterrâneo de combustível.

No que se refere ao mapeamento de tanques antigos, essa variante classificou-se como "não se aplica", visto que se trata de um PRC que possuiu licenças ambientais anteriores, como a Licença Prévia e a Licença de Instalação, tendo sido construído em uma área onde anteriormente eram desenvolvidos outros tipos de atividades. Já no que diz respeito à variante sistema de monitoramento ambiental, esse também é um item “conforme”. Há sensores instalados nas áreas específicas, cujo console, que alarma quando há quaisquer vazamentos, encontra-se no escritório. Todavia, no que diz respeito à variante câmara de contenção, apesar de terem sido colocadas sob cada uma das quatro bombas e dos dois filtros de diesel, elas foram danificadas (furadas) para a passagem de fios e, assim, encontram-se "não conforme".

A Figura 2 apresenta imagens comparativas da parte interna de duas bombas de abastecimento de combustíveis, uma sem câmara de contenção e a outra, referente ao Posto Terra do Sal, com a câmara danificada.

Figura 2 - Câmara de contenção (sump) de bomba ausente (A) e presente, mas danificada (B).
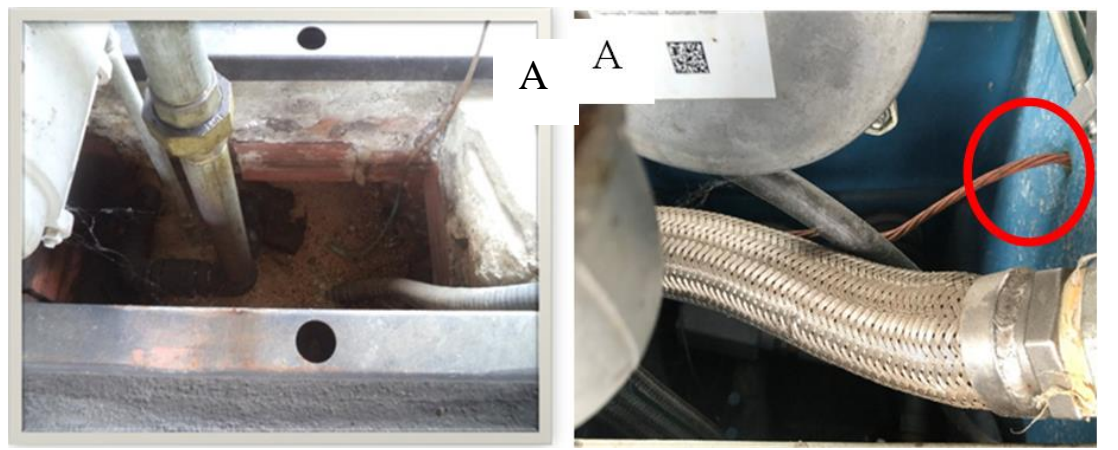

B

Fonte: Elaboração própria em 2019.

É importante destacar na Figura 2 (A) a inexistência de câmara de contenção, uma caixa estanque que impede que o combustível infiltre no solo. Já na Figura 2 (B), a câmara (de cor azul) foi instalada, mas foi danificada quando realizaram um furo para a passagem do fio (círculo vermelho), podendo trazer risco à vida humana e ao meio ambiente circundantes. 


\subsection{Proteção contra derramamento}

O Posto Terra do Sal apresentou-se em conformidade com as normas ambientais em relação à categoria de proteção contra derramamento nas variáveis: piso impermeabilizado, canaletas e breakaways, estando todos em bom estado de conservação e funcionais.

Contudo, apesar de ter uma caixa separadora de água e óleo instalada, observou-se durante a vistoria que há a necessidade de realização de manutenção para um funcionamento eficiente, pois o resíduo oleoso não está sendo separado, indo de encontro com a norma técnica 14605-2 (ABNT, 2010). Os skimmers constantes nessa caixa devem ser posicionados acima da película oleosa, sendo imersos periodicamente para a retirada desse óleo que, por ser menos denso que a água, se mantém na parte superior do efluente. O óleo segue dos skimmers para o módulo coletor de óleo, onde deve ser retirado e armazenado em recipientes estanques, até sua coleta por empresa licenciada para o transporte e destinação final. A água livre do resíduo oleoso deve ser conduzida para o sumidouro.

Sendo assim, o Posto Terra do Sal enquadrou-se como "não conforme" para a variante caixa separadora de água e óleo, conforme pode ser constatado na imagem B da Figura 3.

Figura 3 - Caixa separadora funcionando corretamente (A) e a do Posto Terra do Sal (B).
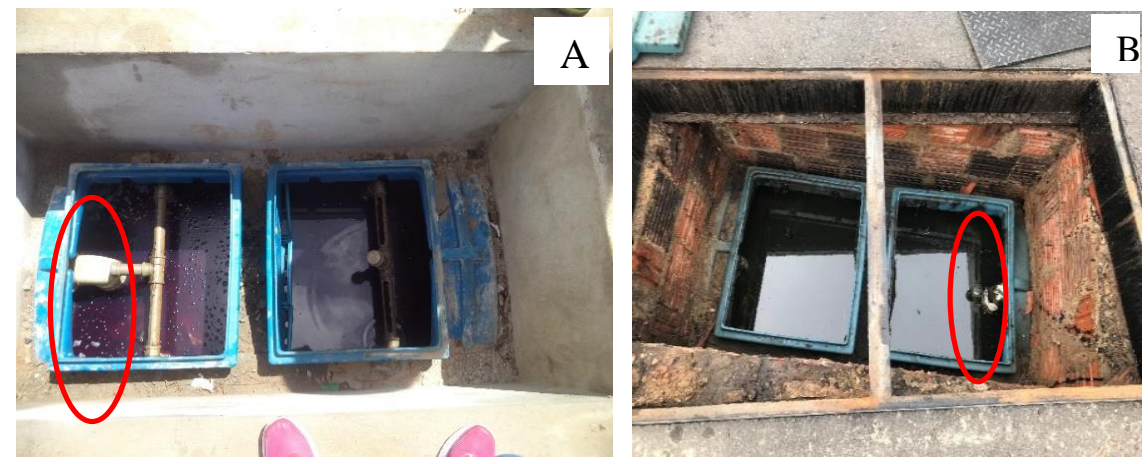

Fonte: Elaboração própria em 2019.

$\mathrm{Na}$ imagem $\mathrm{B}$ da Figura 3, tem-se o posicionamento incorreto dos skimmers do Posto Terra do Sal (destaque em vermelho), que estavam submersos. Em contrapartida, temos na imagem A os skimmers localizados corretamente, usada como parâmetro. 


\subsection{Proteção contra transbordamento}

Em se tratando da categoria proteção contra transbordamento, todas as duas variáveis se apresentaram de modo "conforme" no Posto Terra do Sal. O dispositivo para descarga selada evita folgas no encaixe da mangueira do caminhão-tanque com o local de descarrego no tanque subterrâneo, tornando-se, assim, tanto uma proteção contra transbordamento quanto contra a poluição atmosférica, uma vez que evita que os vapores de combustíveis sejam liberados para o ar. Já a variável câmara de contenção de descarga (ou spill container) retém possíveis transbordamentos ocorridos durante a operação de descarrego de combustíveis.

\subsection{Proteção contra poluição atmosférica}

Além da variável denominada como dispositivo de descarga selada, mencionada anteriormente, a válvula de contenção de vapores atua na proteção contra poluição atmosférica. Essas válvulas estão presentes nos respiros dos tanques, evitando que os gases de combustível emanados desses reservatórios sejam liberados na atmosfera. As duas variáveis dessa categoria estão ambientalmente adequadas no Posto Terra do Sal.

Ressalta-se, pois, que no Posto Terra do Sal o empreendedor instalou um sump nos respiros dos tanques para proteção de possíveis vazamentos (Figura 4). Trata-se de uma novidade no mercado que visa majorar a proteção à poluição. Todavia, não há ainda previsão legal para isso, como também não foi requerido na Licença de Instalação do posto, emitida pelo IDEMA. 
Figura 4 - Respiros de tanque não adequados (A), adequados (B) e os respiros do Posto Terra do Sal (C e D).

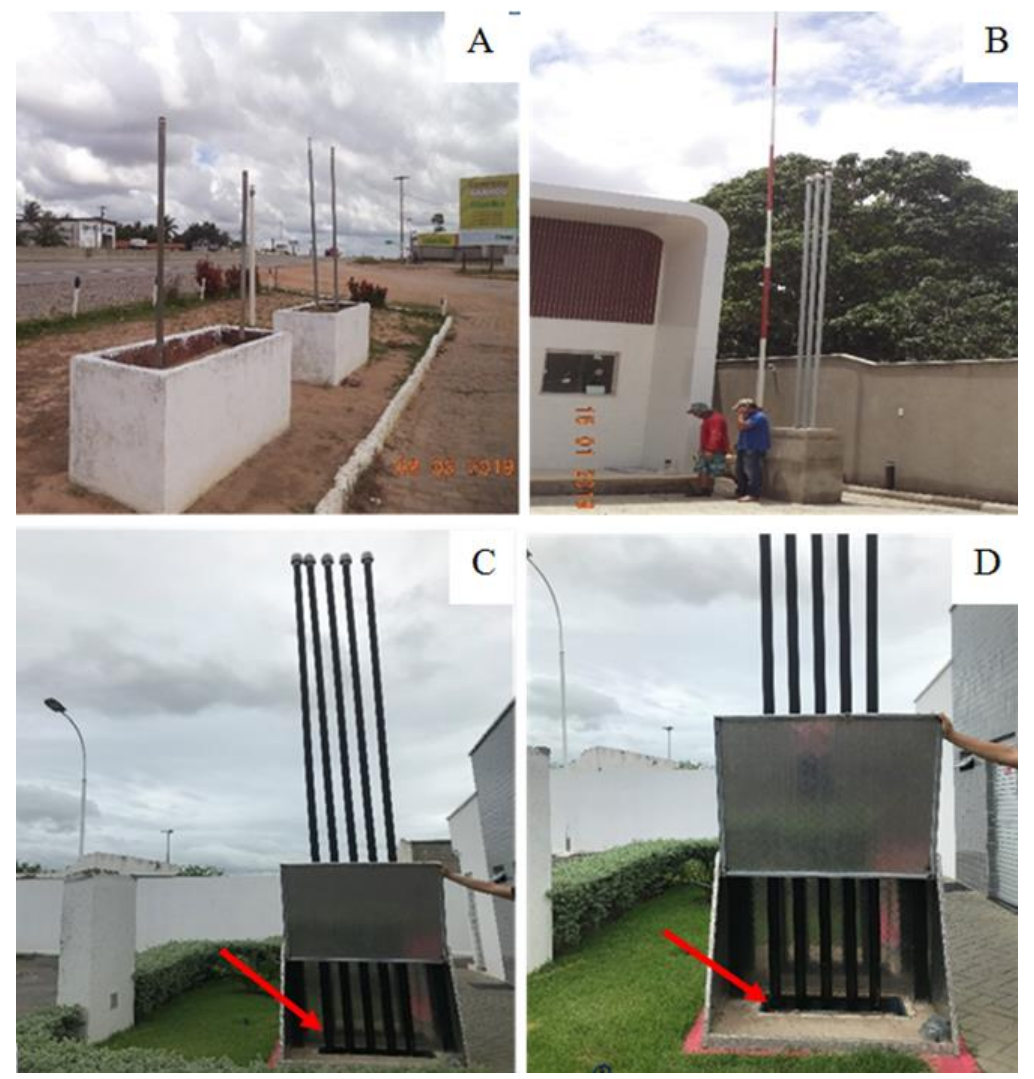

Fonte: Elaboração própria em 2019.

Cabe destacar na Figura 4 as imagens $\mathrm{C}$ e D, nas quais se pode observar que no Posto Terra do Sal foi instalado, por iniciativa do empreendedor, um sump sob os respiros dos tanques (seta vermelha).

Considerando a categoria de redução de riscos e que a área de um PRC possui uma atmosfera explosiva decorrente da volatilidade dos combustíveis, há a necessidade de que os equipamentos nela constantes sejam adequados. Há ainda a preocupação com possíveis colisões de veículos com os respiros de tanques.

Nesse sentido, com relação às variantes que objetivam minorar os riscos em um PRC, como proteção contra abalroamento dos respiros dos tanques, eletrodutos e tomadas à prova de explosão e aterramento para energia eletrostática dos caminhões, o Posto Terra do Sal encontra-se ambientalmente adequado.

O Posto Terra do Sal passou pelas etapas sequenciais previstas na CONAMA 237 (Brasil, 2010; Milaré, 2015): Licença Prévia, Licença de Instalação e Licença de Operação, sendo essa última a licença atual do empreendimento. Essa LO foi emitida pelo IDEMA em janeiro de 2018, a qual autorizou o início das atividades e possui validade de 04 anos 
contados da sua emissão. Compulsando os autos do licenciamento, observou-se que, além da LO válida, o proprietário do Posto Terra do Sal tem atendido às condicionantes estabelecidas nesse ato administrativo dentro dos prazos previstos.

Assim, o Posto Terra do Sal encontra-se conforme para essa categoria, cuja variável é LO. Já no que diz respeito à variável LRO, esta não se aplica, pois cabe apenas a empreendimentos que nunca tiveram licença ambiental. Mesmo diante da gama de tipos de licenças existentes no Rio Grande do Norte para o licenciamento de PRCs, foram selecionadas apenas LO e LRO como variáveis, visto que apenas essas duas autorizam a operação, o funcionamento das empresas revendedoras de combustíveis nesse estado.

O Estudo de Investigação de Passivo Ambiental é uma ferramenta usada para constatar a existência de hidrocarbonetos derivados do petróleo no subsolo da área do PRC, oriunda de contaminação por vazamentos, nos tanques e/ou tubulações, ou derramamentos de combustíveis e de lubrificantes. Esse estudo é exigido para PRCs que estão em operação, mas nunca possuíram uma licença ambiental, assim como para áreas que já abrigaram um PRC no passado e que agora se pretende instalar um novo.

O Passivo Ambiental é um estudo que não só identifica os contaminantes, mas também os quantifica, determina a extensão da pluma de contaminação no subsolo e indica as técnicas de remediação da contaminação a ser utilizadas. O termo de referência para a elaboração desse estudo, no estado do RN, encontra-se na Resolução CONEMA 06 (Rio Grande do Norte, 2011). Desse modo, como o Posto Terra do Sal não se enquadra nesses dois casos mencionados, ele se classifica como "não se aplica" para a categoria Estudo de Investigação de Passivo Ambiental.

Os empresários que possuem um PRC têm obrigação de promover o treinamento de seus funcionários em operação, em manutenção e em resposta a incidentes (ABNT, 2006; Brasil, 2000; 2018). A necessidade de realização desse treinamento consta na condicionante número 08 da LO do Posto Terra do Sal, a qual foi atendida no prazo estabelecido. Constatado isso, o Posto Terra do Sal encontra-se conforme para essa variável.

Essa última categoria, destinação dos resíduos da classe I, tem duas variáveis que são os resíduos sólidos (trapos, embalagens, areia, filtros de óleo) e os líquidos (efluente oleoso da caixa separadora de água e óleo, óleo lubrificante usado e contaminado). Esses resíduos necessitam ser acondicionados separadamente, recolhidos, transportados e entregues à empresa licenciada para promover sua destinação final, com o intuito de evitar contaminação ao ambiente. O óleo lubrificante usado e contaminado deve ser encaminhado para o rerrefino, 
(CC BY 4.0) | ISSN 2525-3409 | DOI: http://dx.doi.org/10.33448/rsd-v9i7.3527

processo no qual esse óleo passa para a remoção de contaminantes, produtos destrutivos e de aditivos dos lubrificantes (Brasil, 2010; 2019).

O Posto Terra do Sal possui recipientes grandes para a coleta de resíduos comuns e resíduos sólidos classe I. Porém, os recipientes não são de material estanque, o que os deixa vulneráveis à degradação e possíveis vazamentos.

Além disso, estavam alocados em área com piso permeável e não estava havendo segregação correta do resíduo contaminado daquele comum. No que concerne aos resíduos líquidos, havia, no PRC, uma bombona (recipiente reservado ao transporte e armazenamento de gases ou produtos químicos) estanque para seu armazenamento temporário, até ser recolhido pela empresa especializada.

Contudo, o mau funcionamento da caixa separadora de água e óleo fez com que o efluente final, conduzido ao sumidouro, fosse considerado classe I por não ter sido tratado corretamente. Logo, observou-se que o Posto Terra do Sal estava "não conforme" para as duas variantes e, consequentemente, para a categoria de resíduos da classe I (perigosos), conforme Figura 5.

Figura 5 - Armazenamento adequado dos resíduos da classe I (A) e não adequado (B).
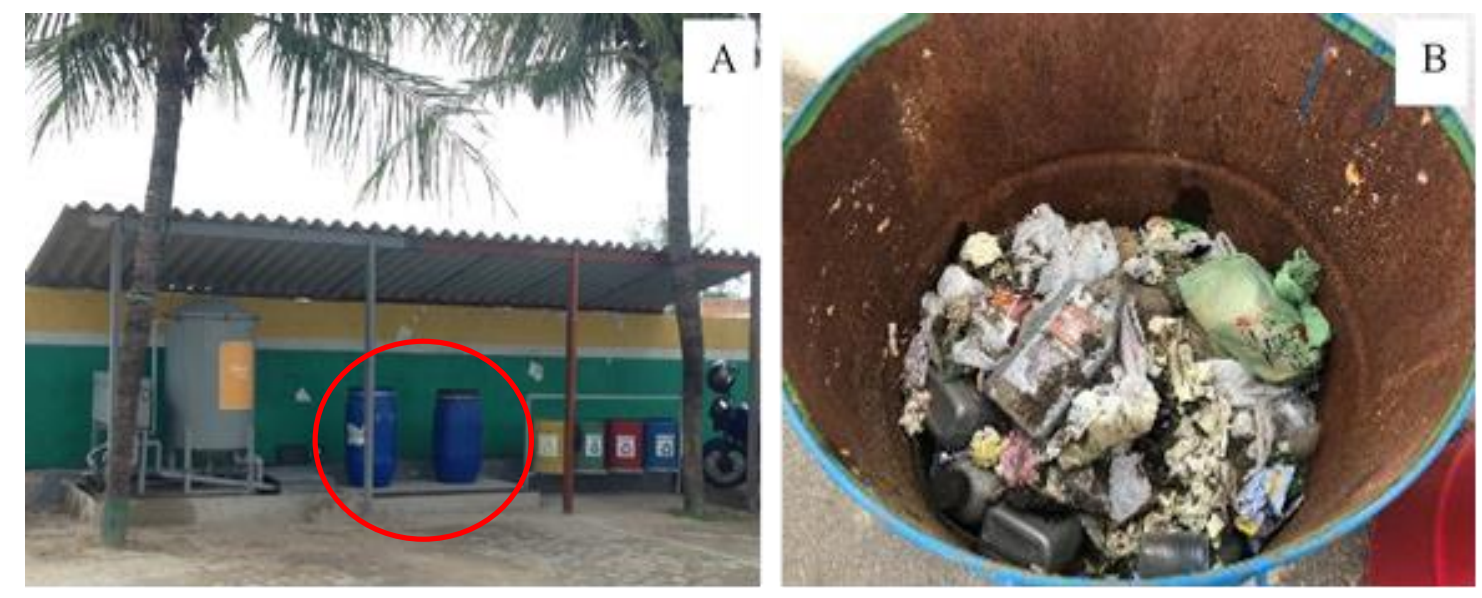

Fonte: Elaboração própria em 2019.

Na imagem A, observa-se um PRC com uma área reservada para armazenamento das bombonas que acondicionam os resíduos líquidos e sólidos classe I (destaque vermelho). Contudo, no Posto Terra do Sal (imagem B), o recipiente não é estanque e não há separação de resíduo perigoso de não perigoso, sendo todos encaminhados à coleta pública. 
Research, Society and Development, v. 9, n. 7, e368973527, 2020

(CC BY 4.0) | ISSN 2525-3409 | DOI: http://dx.doi.org/10.33448/rsd-v9i7.3527

De modo a permitir uma visão melhor acerca da coletânea dos resultados obtidos no Posto Terra do Sal, foi sintetizado no Quadro 1 tais conclusões, as quais classificam as categorias e suas variantes analisadas em "conforme", "não conforme" e "não se aplica".

Quadro 1 - Situação ambiental do Posto Terra do Sal.

\begin{tabular}{|c|c|c|c|c|}
\hline CATEGORIAS & VARIANTES & CONFORME & $\begin{array}{c}\text { NÃO } \\
\text { CONFORME }\end{array}$ & $\begin{array}{l}\text { NÃO SE } \\
\text { APLICA }\end{array}$ \\
\hline \multirow{5}{*}{$\begin{array}{c}\text { PROTEÇÃO CONTRA } \\
\text { VAZAMENTOS }\end{array}$} & $\begin{array}{l}\text { Tanques } \\
\text { ecológicos }\end{array}$ & $\mathbf{X}$ & & \\
\hline & $\begin{array}{c}\text { Câmara de } \\
\text { contenção } \\
\text { (bombas e filtros) }\end{array}$ & & $\mathbf{X}$ & \\
\hline & $\begin{array}{c}\text { Sistema de } \\
\text { monitoramento } \\
\text { ambiental }\end{array}$ & $\mathbf{X}$ & & \\
\hline & $\begin{array}{c}\text { Teste de } \\
\text { estanqueidade e } \\
\text { integridade }\end{array}$ & $\mathbf{X}$ & & \\
\hline & $\begin{array}{l}\text { Mapeamento de } \\
\text { tanques antigos }\end{array}$ & & & $\mathbf{X}$ \\
\hline \multirow{4}{*}{$\begin{array}{c}\text { PROTEÇÃO CONTRA } \\
\text { DERRAMAMENTOS }\end{array}$} & $\begin{array}{l}\text { Piso de concreto } \\
\text { impermeabilizado }\end{array}$ & $\mathbf{X}$ & & \\
\hline & Canaletas & $\mathbf{X}$ & & \\
\hline & $\begin{array}{l}\text { Caixa separadora } \\
\text { de água e óleo }\end{array}$ & & $\mathbf{X}$ & \\
\hline & Breakaway & $\mathbf{X}$ & & \\
\hline \multirow{2}{*}{$\begin{array}{c}\text { PROTEÇÃO CONTRA } \\
\text { TRANSBORDAMENTO }\end{array}$} & $\begin{array}{l}\text { Dispositivo para } \\
\text { descarga selada }\end{array}$ & $\mathbf{X}$ & & \\
\hline & $\begin{array}{l}\text { Câmara de } \\
\text { contenção de } \\
\text { descarga }\end{array}$ & $\mathbf{X}$ & & \\
\hline \multirow[b]{2}{*}{$\begin{array}{c}\text { PROTEÇÃO CONTRA } \\
\text { POLUIÇÃO } \\
\text { ATMOSFÉRICA }\end{array}$} & Descarga selada & $\mathbf{X}$ & & \\
\hline & $\begin{array}{l}\text { Válvulas de } \\
\text { contenção de } \\
\text { vapores }\end{array}$ & $\mathbf{X}$ & & \\
\hline \multirow{2}{*}{ RISCOS } & $\begin{array}{l}\text { Eletrodutos e } \\
\text { tomadas à prova } \\
\text { de explosão }\end{array}$ & $\mathbf{X}$ & & \\
\hline & $\begin{array}{l}\text { Proteção contra } \\
\text { abalroamento nos } \\
\text { respiros }\end{array}$ & $\mathbf{X}$ & & \\
\hline \multirow{2}{*}{$\begin{array}{c}\text { LICENÇA AMBIENTAL } \\
\text { VÁLIDA }\end{array}$} & LO & $\mathbf{X}$ & & \\
\hline & LRO & & & $\mathbf{X}$ \\
\hline $\begin{array}{c}\text { ESTUDO DE } \\
\text { INVESTIGAÇÃO DE }\end{array}$ & & & & $\mathbf{X}$ \\
\hline
\end{tabular}




\section{PASSIVO AMBIENTAL}

TREINAMENTO DE PESSOAL

\section{DESTINO FINAL RESÍDUOS CLASSE I}

$\mathbf{X}$

Fonte: Autores (2020).

O Quadro 1 sintetiza a situação ambiental do Posto Terra do Sal, evidenciando as categorias e suas respectivas variantes. Cabe ressaltar que as categorias Estudo de Investigação de Passivo Ambiental e Treinamento de Pessoal não possuem variantes, pois não há subdivisão nessas duas categorias. Diante do exposto, constatou que o PCR está apresentando uma situação mais adequada ambientalmente, devido as suas atividades estarem mais em consonância ou em conformidade como ditames normativos e legais e às condições do meio ambiente circundante.

Ou seja, analisando os resultados obtidos, pode-se perceber que o Posto Terra do Sal apresenta muito mais conformidades que não conformidades. Esse PRC não havia tido, no entanto, sua conformidade atestada pelo MP-RN, mas ao usar a matriz do checklist (Dias, 2012), que se destaca por ser bastante detalhada e embasada nas normas ambientais, esse PRC se mostrou parcialmente não conforme, apenas.

As câmaras de contenção de bombas e filtros, por exemplo, foram instaladas, mas tiveram sua estanqueidade violada por terem sido furadas para a passagem de fios (Abnt, 2014; 2019). Quando danificadas, essas câmaras podem permitir que qualquer combustível se infiltre no subsolo e cause impactos negativos ao solo e à água subterrânea. A depender do fluxo dessa água, a contaminação pode atingir o abastecimento humano mesmo a grandes distâncias (Corseuil et al., 2011; Freire, Trannin \& Simoes, 2014) e a ingestão ou o contato com as substâncias químicas presentes nos combustíveis podem desencadear diversas doenças, devido à alta toxicidade dos hidrocarbonetos (Amaral et al., 2017; Costa \& Goldbaum, 2017; Maksoud et al., 2019; Skamvetsakis et al., 2017; Sousa \& Cardoso, 2017; Zucki et al., 2017).

Investigando os autos do licenciamento ambiental do Posto Terra do Sal, pôde-se observar que, quando o empreendedor solicitou a Licença de Operação, foi vistoriado pelo IDEMA, que solicitou que fosse instalado o sistema de monitoramento ambiental. $\mathrm{O}$ proprietário do PRC comprovou documentalmente o atendimento à solicitação do IDEMA e, 
assim, obteve sua Licença de Operação. Não houve nova vistoria após a instalação desse sistema.

Dessa forma, é provável que as câmaras de contenção tenham sido danificadas nesse interim entre a vistoria do IDEMA e a implantação do monitoramento ambiental. Uma forma simples de se evitar a violação às câmaras (sumps) de bombas e filtros seria incluir na Relação de Documentos Básicos para o Licenciamento Ambiental, da licença de operação, a instalação do sistema de monitoramento ambiental. Essa relação é uma lista de documentos imprescindíveis à abertura do processo de LO. Assim, quando o empreendimento fosse vistoriado pelo IDEMA, seria identificada a conformidade ou não daquelas câmaras. Em caso negativo, seria solicitada a substituição dessas antes do início das atividades do PRC.

Além disso, a caixa separadora de água e óleo, uma das variáveis, foi instalada, mas encontra-se ineficiente por não operar de acordo com a NBR 14605-2 (Abnt, 2010). O Código de Obras, Posturas e Edificações do Município de Mossoró (Mossoró, 2010) permite que o efluente final da caixa separadora de água e óleo tenha como destino a rede de esgoto municipal.

Contudo, cabe ressaltar que na companhia de abastecimento de água não há tratamento para remoção dos hidrocarbonetos; que o benzeno, por exemplo, é nocivo à saúde humana mesmo em pequenas concentrações (Amaral et al., 2017; Maksoud et al. 2019); e, principalmente, que ainda que fossem mensuradas as concentrações daquelas substâncias químicas na estação de tratamento de esgotos, não haveria como saber qual dos 56 PRC do município seria o responsável pela contaminação, podendo ainda configurar-se como uma poluição difusa.

Para o IDEMA, a destinação do efluente tratado na caixa separadora de água e óleo de um PRC deve ser o sumidouro. No Posto Terra do Sal, o efluente oleoso (perigoso) tem sido destinado a ele, mas sem a separação do óleo, devido a ineficiência da caixa. Compulsando os autos processuais, durante a análise documental, pôde-se observar que o licenciamento ambiental realizado pelo IDEMA ocorreu em consonância com as normas ambientais vigentes. Todavia, é imprescindível uma ação mais efetiva no que se refere à fiscalização do órgão ambiental, após a emissão da licença, com a finalidade de coibir infrações como essa através de vistorias periódicas. Há ainda a necessidade de o empreendedor implantar um programa de gestão ambiental no PRC, a fim de detectar e sanar quaisquer alterações durante o funcionamento dessa organização.

Por último, observou-se que a destinação dos resíduos classe I tem se dado de forma inadequada em relação à NBR 10004:4 e a resolução CONAMA 362 (Abnt, 2004; Brasil, 
2005). Esses resíduos perigosos devem ser armazenados em recipientes resistentes à vazamentos, coletados e transportados por empresa licenciada para essa atividade, cujo destino final deve ser um aterro industrial. Contudo, no Posto Terra do Sal eles estão sendo coletados pela prefeitura, já que estão acondicionados com os resíduos comuns.

Apesar de existirem recipientes para a coleta segregada dos resíduos perigosos e não perigosos no Posto Terra do Sal, a ausência de gestão ambiental na empresa pode ter permitido esse descarte irregular. Além disso, mais uma vez se fazem necessárias ações consistentes do órgão ambiental no sentido de fiscalizar o funcionamento desses empreendimentos, a fim de evitar a ocorrência de possíveis crimes ambientais.

\section{Considerações Finais}

Conclui-se, portanto, que apesar do Posto Terra do Sal encontrar-se parcialmente inadequado ambientalmente, as alterações para que ele exerça suas atividades de forma sustentável são pequenas e referem-se à substituição das câmaras de contenção de bombas e de filtros, à manutenção na caixa separadora de água e óleo, isso feito por um técnico habilitado, e à aquisição de recipientes (bombonas) estanques para acondicionamento seguro e segregado dos resíduos sólidos e líquidos classe I. Além disso, os resíduos devem ser coletados e conduzidos à empresa destinadora final que possua licença ambiental.

Destaca-se que o Posto Terra do Sal inovou instalando câmara de contenção (sump) nos respiros dos tanques, com fins de proteção de possíveis vazamentos, mesmo não havendo previsão legal, como também requisição pelo órgão ambiental. Todavia, foi negligente no que que concerne a gestão ambiental na empresa.

Depreende-se, ainda, que o processo de licenciamento ambiental desenvolvido pelo IDEMA apresenta-se consoante às normas ambientais. Contudo, constatou-se a inexistência de monitoramento ambiental contínuo, por parte do setor de fiscalização do órgão responsável pelo licenciamento ambiental, resultando em possíveis danos ao meio ambiente.

Recomenda-se, portanto, ao posto de revenda de combustíveis e ao órgão ambiental licenciador intervenções em direção à sustentabilidade. Ao primeiro, procurou-se indicar a substituição, manutenção e/ou aquisição de equipamentos tecnológicos que melhor se adequem às condições ambientais do posto; ao segundo, foram sugeridas estratégias para uma melhor tomada de decisão quanto às ações de monitoramento e fiscalização, adequando-se ambientalmente e aos preceitos legais. Essas estratégias sugeridas referem-se a vistorias periódicas a serem realizadas após a emissão da licença ambiental, com a finalidade de coibir 
infrações relacionadas a danos ou ineficiência de equipamentos instalados e à destinação inadequada de resíduos da classe I (perigosos). Além disso, sugerem-se alterações das Instruções Técnicas com o intuito de atualizar e uniformizar todo o processo de licenciamento ambiental de postos de revenda de combustíveis locais.

\section{Referências}

ANP. (2019). Anuário Estatístico Brasileiro do Petróleo e do Gás Natural e Biocombustíveis 2019. Disponível em https://www.scielo.br/pdf/rbso/v42s1/2317-6369-rbso-42-e8s.pdf. Acesso em: 1 abril 2020.

Amaral, ICC et al. (2017). Avaliação ambiental de BTEX (benzeno, tolueno, etilbenzeno, xilenos) e biomarcadores de genotoxicidade em trabalhadores de postos de combustíveis. Revista Brasileira de Saúde Ocupacional, 42, 1-14. Disponível em http://dx.doi.org/10.1590/2317-6369000124515. Acesso em: 20 março 2020.

ABNT. (2014). NBR 13786: Posto de serviço: Seleção dos equipamentos para sistemas para instalações subterrâneas de combustíveis. Associação Brasileira de Normas Técnicas. Rio de Janeiro: ABNT.

ABNT. (2019). NBR 16764: Armazenamento de líquidos inflamáveis e combustíveis: Instalação dos componentes do sistema de armazenamento subterrâneo de combustíveis (SASC), óleo lubrificante usado e contaminado (OLUC) e ARLA 32. Associação Brasileira de Normas Técnicas. Rio de Janeiro: Abnt.

ABNT. (2010). NBR 14605-2: Armazenamento de líquidos inflamáveis e combustíveis: Sistema de drenagem oleosa. Associação Brasileira de Normas Técnicas. Rio de Janeiro: Abnt.

ABNT. (2014). NBR 14639: Armazenamento de líquidos inflamáveis e combustíveis: Posto revendedor veicular (serviços) e ponto de abastecimento: Instalações elétricas. Associação Brasileira de Normas Técnicas. Rio de Janeiro ABNT. 
ABNT. (2013). NBR 5598: Eletroduto de aço-carbono e acessórios, com revestimento protetor e rosca BSP: Requisitos. Associação Brasileira de Normas Técnicas. Rio de Janeiro: ABNT.

ABNT. (1994). NBR 12236: Critérios de projeto, montagem e operação de postos de gás combustível comprimido: Procedimento. Associação Brasileira de Normas Técnicas. Rio de Janeiro: ABNT.

ABNT. (2006). NBR 14276: Brigada de incêndio: Requisitos. Associação Brasileira de Normas Técnicas. Rio de Janeiro: Abnt.

ABNT. (2004). NBR 10004: Resíduos sólidos: Classificação. Associação Brasileira de Normas Técnicas. Rio de Janeiro: Abnt.

Barros, PEO. (2006). Diagnóstico ambiental para postos de abastecimento de combustíveis (Dissertação de mestrado, Universidade do Vale do Itajaí, Santa Catarina, Brasil).

Brasil. (1997). Resolução $n^{o} 237$, de 19 de dezembro de 1997. Disponível em http://www.mma.gov.br/port/conama/legiabre.cfm?codlegi=237. Acesso em: 1 abril 2020.

Brasil. (2000). Resolução $n^{\circ} 273$, de 29 de novembro de 2000. Disponível em http://www.mma.gov.br/port/conama/legislacao/CONAMA_RES_CONS_2000_273.pdf. Acesso em: 1 março 2020.

Brasil. (2005). Resolução $n^{o} 362$, de 23 de junho de 2005. Disponível em http://www2.mma.gov.br/port/conama/legiabre.cfm?codlegi=466. Acesso em: 1 março 2020.

Brasil. (2009). Resolução no 420, de 30 de dezembro de 2009. Disponível em http://www.mma.gov.br/port/conama/legiabre.cfm?codlegi=620. Acesso em: 15 janeiro 2020.

Brasil. (1988). Constituição da República Federativa do Brasil de 1988. Disponível em http://www.planalto.gov.br/ccivil_03/constituicao/constituicao.htm. Acesso em: 1 janeiro 2020. 
Brasil. (2011). Lei Complementar no 140, de 8 de dezembro de 2011. Disponível em http://www.planalto.gov.br/ccivil_03/leis/lcp/lcp140.htm. Acesso em: 1 janeiro 2020.

Brasil. (1981). Lei $n^{o}$ 6.938, de 31 de agosto de 1981. Disponível em http://www2.mma.gov.br/port/conama/legiabre.cfm?codlegi=313. Acesso em: 1 janeiro 2020.

Corseuil, HX, Monier, AL, Fernandes, M, Schneider, MR, Nunes, CC, Rosário, M \& Alvarez, PJJ. (2011). BTEX plume dynamics following an ethanol blend release: geochemical footprint and thermodynamic constraints on natural attenuation. Environmental Science and Technology, 45, 3422-3429. Disponível em http://dx.doi.org/10.1021/es104055q. Acesso em: 1 janeiro 2020.

Corseuil, HX \& Marins, MDM. (1997). Contaminação de águas subterrâneas por derramamentos de gasolina: o problema é grave. Engenharia Sanitária e Ambiental, 2, 50-54. Disponível em: http://13ambiental.com.br/wp-content/uploads/2017/01/Contaminacao-deAguas.pdf. Acesso em: 1 janeiro 2020.

Costa, DF \& Goldbaum, M. (2017). Contaminação química, precarização, adoecimento e morte no trabalho: benzeno no Brasil. Ciência \& Saúde Coletiva, 22, 2681-2692. Disponível em: http://www.scielo.br/scielo.php?script=sci_arttext\&pid=S1413$81232017002802681 \& \operatorname{lng}=$ pt\&tlng=pt. Acesso em: 1 março 2020.

Dias, GM. (2012). Adequação ambiental de postos de combustíveis de Natal e recuperação da área degradada. Disponível em:

http://www.mprn.mp.br/controle/file/2013/CEAF/Adequacao_Ambiental_Postos_Combustive is_Gilka_da_Mata.pdf. Acesso em: 1 janeiro 2020.

Freire, PAC, Trannin, ICB \& Simões, SJC. (2014). Bombeamento e tratamento da fase livre em Aquífero Litorâneo. Engenharia Sanitária e Ambiental, 19, 461-470. Disponível em http://www.scielo.br/scielo.php?script=sci_arttext\&pid=S1413$41522014000400461 \& \operatorname{lng}=e n \& n r m=i s o$. Acesso em: 1 abril 2020. 
Guerra, AR \& Fontes, FA. (2017). Eco-labelling of petrol stations: a sucessful experience in Brazil. In: Soil Remediation Applications and New Technologies. 1st edition. Boca Raton. CRC Press.

Heibati, B, Pollittb, KJG, Charatic, JY, Ducatmand, A, Shokrzadehe, M, Karimif, A \& Mohammadyang, M. (2018). Biomonitoring-based exposure assessment of benzene, toluene, ethylbenzene and xylene among workers at petroleum distribution facilities. Ecotoxicology and Environmental Safety, 149, 19-25. Disponível em: https://doi.org/10.1016/j.ecoenv.2017.10.070. Acesso em: 15 janeiro 2020.

Kerber, FF. (2013). Atendimento a legislação ambiental em postos de abastecimento de combustíveis: uma contribuição a perícia ambiental criminal (Dissertação de mestrado, Universidade Federal de Santa Catarina, Santa Catarina, Brasil.

Maksoud, HAA et al. (2019). Biochemical study on occupational inhalation of benzene vapours in petrol station. Respiratory Medicine Case Reports, 27, p.1-4, 03 abr. 2019. Elsevier BV. Disponível em: https://doi.org/10.1016/j.rmcr.2019.100836. Acesso em: 17 janeiro 2020 .

Mariano, AP, Angelis, DF \& Bonotto, DM. (2007). Monitoramento de indicadores geoquímicos e avaliação de biodegradação em área contaminada com óleo diesel. Engenharia Sanitária e Ambiental, 12, 296-304. Disponível em http://www.scielo.br/scielo.php?script=sci_arttext\&pid=S141341522007000300009\&lng=en\&nrm=iso. Acesso em: 15 março 2020.

Milaré, É. (2015). Direito do ambiente. São Paulo, Brasil: Editora Revista dos Tribunais.

Mossoró. (2006). Lei Complementar nº 012, de 11 de dezembro de 2006. Plano diretor de Mossoró. Disponível em https://www.secovirn.com.br/legislacao/plano-diretor-demossoro.pdf. Acesso em: 1 maio 2020.

Mossoró. (2010). Lei Complementar n 47, de 16 de dezembro de 2010. Código de obras, posturas e edificações do município de Mossoró. Disponível em https://leismunicipais.com.br/a/rn/m/mossoro/lei-complementar/2010/4/47/lei-complementar- 
n-47-2010-dispoe-sobre-o-codigo-de-obras-posturas-e-edificacoes-do-municipio-de-mossoro2010-12-16. Acesso em: 15 maio 2020.

Pereira, AS, Shitsuka, DM, Parreira, FJ \& Shitsuka, R. (2018). Metodologia da pesquisa científica. [e-book]. Disponível em https://repositorio.ufsm.br/bitstream/handle/1/15824/Lic_Computacao_MetodologiaPesquisa-Cientifica.pdf?sequence=1. Acesso em: 15 maio 2020.

Rio Grande do Norte. (2004). Lei Complementar $n^{\circ}$ 272, de 3 de março de 2004. Diário Oficial do Estado. Disponível em http://www.mprn.mp.br/portal/inicio/noticias/5772-5772mp-inicia-projeto-para-adequacao-ambiental-de-postos-em-mossoro. Acesso em: 15 maio 2020.

Rio Grande do Norte. (2011). Resolução no 06, de 14 de dezembro de 2011. Disponível em: https://sogi8.sogi.com.br/Arquivo/Modulo113.MRID109/Registro1258882/conema.pdf. Acesso em: 30 março 2020.

Skamvetsakis, A et al. (2017). Exposição ao benzeno em postos de combustíveis: estratégia de ações integradas de vigilância em saúde do trabalhador na região dos Vales/RS. Revista Brasileira de Saúde Ocupacional, 42, 1-11. Disponível em http://dx.doi.org/10.1590/23176369000126015. Acesso em: 27 janeiro 2020.

Sousa, FNF \& Cardoso, MCB. (2017). Vigilância da exposição ao benzeno em ambientes e processos de trabalho de postos de combustíveis: relato de experiência do Cerest/Itaberaba, Bahia. Revista Brasileira de Saúde Ocupacional, 42, 1-12. Disponível em: http://dx.doi.org/10.1590/2317-6369000123815. Acesso em: 25 março 2020.

Souza, SKS \& Silva, VP. (2018). Posto de revenda de combustíveis e adequação ambiental: algumas discussões teóricas. Anais Congresso Nacional de Meio Ambiente de Poços de Caldas, Poços de Caldas, Minas Gerais, Brasil, 10. Disponível em http://www.meioambientepocos.com.br/Anais2018/home.html. Acesso em: 15 maio 2020.

Trennepohl, C \& Trennepohl, T. (2016). Licenciamento ambiental. São Paulo, Brasil: Editora Revista dos Tribunais. 
Yin, R. (2015). Estudo de caso: Planejamento e métodos. Porto Alegre, Brasil: Bookman.

Zucki, F et al (2017). Caracterização do perfil auditivo de frentistas de postos de combustível. Audiology - Communication Research, 22, 1-7. Disponível em http://dx.doi.org/10.1590/2317-6431-2016-1759. Acesso em: 15 maio 2020.

\section{Porcentagem de contribuição de cada autor no manuscrito}

Valdenildo Pedro da Silva - 40\%

Sharlene Karla dos Santos Souza - 60\% 